\title{
Are clarithromycin, azithromycin and their analogues effective in the treatment of COVID19?
}

\author{
Gedikli MA ${ }^{1}$, Tuzun $\mathrm{B}^{2}$, Aktas $\mathrm{A}^{1}$, Sayin $\mathrm{K}^{2,3}$, Ataseven $\mathrm{H}^{4}$ \\ Sivas Cumhuriyet University, Faculty of Science, Department of Chemistry, Sivas, Turkey. krysayin@gmail.com
}

\begin{abstract}
BACKGROUND: SARS-CoV-2, which started in Wuhan and later affected the whole world, is the most important disease of the world today. Many ways to inhibit SARS-CoV-2 virus are sought to prevent the spread of this virus. Azithromycin and clarithromycin are considered for the treatment of the SARS-CoV-2 virus, which has a high similarity to previous colonic diseases.

AIM: We aimed to determine whether azithromycin and clarithromycin, the RNA-dependent RNA polymerase protein inhibitor used in the treatment of COVID-19, is effective against SARS Cov-2 in silico.

RESULTS AND CONCLUSION: The 503 analogues of azithromycin and clarithromycin were studied to target SARS-CoV-2 the RNA-dependent RNA polymerase protein inhibition. Maestro program was used to compare the inhibition activities of these analogues. A detailed comparison was made using the numerical value of many parameters obtained. ADME / T properties were then examined to determine the effects and reactions of analogues on human metabolism. In this study, the SARS-CoV2 virus is 6NUR and 6NUS, which is the RNA-dependent RNA polymerase protein. Among these proteins, the best inhibitor among the 503 analogues according to the docking score parameter was 9851445 with a great difference. This analogue was an analogue of azithromycin (Tab. 3, Fig. 6, Ref. 58). Text in PDF www.elis.sk

KEY WORDS: SARS-CoV-2, RNA-dependent RNA polymerase, Azithromycin, Clarithromycin, COVID19.
\end{abstract}

\section{Introduction}

At the end of December 2019, a new outbreak occurred in Wuhan, Hubei province, in China, with unknown causes and treatment-resistant pneumonia findings. It was observed that the agent that caused this outbreak belonged to the same subfamily as SARS-CoV, which is a member of the Coronaviridae family and originated in China in 2002 (1).

Coronaviruses are enveloped RNA viruses. There are many subtypes of coronaviruses. Six subtypes of coronaviruses (229E, OC43, NL63, HKU1, SARS-CoV, MERSCoV) are known to cause disease in humans (2). Coronaviruses consists of four structural proteins: nucleocapsid, envelope, membrane, and spines.

On December 31, 2019, the World Health Organization (WHO) China Country Office reported pneumonia cases of unknown

${ }^{1}$ Department of Internal Medicine, Faculty of Medicine, Sivas Cumhuriyet University, Sivas, Turkey, ${ }^{2}$ Department of Chemistry, Faculty of Science, Sivas Cumhuriyet University, Sivas, Turkey, ${ }^{3}$ Advanced Technology Research and Application Center, Sivas Cumhuriyet University, Sivas, ${ }^{4}$ Department of Gastroenterology, Faculty of Medicine, Sivas Cumhuriyet University, Sivas, Turkey

Address for correspondence: K. Sayin, Ass Prof Dr, Sivas Cumhuriyet University, Faculty of Science, Department of Chemistry, 58140 Sivas, Turkey.

Acknowledgments: This work is supported by the Scientific Research Project Fund of Sivas Cumhuriyet University under the project number RGD-020. aetiology in Wuhan, Hubei province, China. On January 7, 2020, the causative agent was identified as a new Coronavirus (2019$\mathrm{nCoV})$, which has not previously been detected in humans. Later, the name of 2019-nCoV disease was accepted as COVID-19, and the virus was named as SARS-CoV-2 due to its similarity to SARS$\mathrm{CoV}$ (3). Although various antiviral agents have been tried in its treatment, there is no specific treatment effective against this virus yet mostly symptomatic agents are used.

Recently, these drugs have attracted great attention, along with the reveal of the anti-viral effects of macrolides. Both azithromycin and clarithromycin bind to the $50 \mathrm{~S}$ ribosomal subunit in pathogenic microorganisms, inhibiting protein synthesis. Clarithromycin is more effective against gram positive bacteria and tissue penetration is better than other antibiotics in the macrolide group (4). Clarithromycin is recommended as the first line in pneumonia treatment guides, since clarithromycin is more effective in the macrolide group as an antibiotic treatment in pneumonia and especially during epidemic periods, and it is better to use it in addition to penicillin group antibiotics (5). In a limited number of studies, the use of clarithromycin with hydroxychloroquine has been shown to be effective in the treatment $(6,7)$. Combination therapy consisting of oseltamivir, a neuraminidase inhibitor, and clarithromycin or azithromycin, healed a seasonal influenza virus infection earlier. Macrolides such as: erythromycin, clarithromycin and azithromycin have not only anti-bacterial activity, but also have anti-inflammatory and immunomodulatory effects. The efficiency of clarithromycin and azithromycin in the treatment of rhinovirus 
101-110

and influenza virus has been proven (8). The mechanism of action of these drugs are as followed;

- Immunomodulatory effect on inflammatory cells, fibroblasts and epithelial cells,

- Modulation of cytokine / chemokine production,

- inhibition of mucus hypersecretion,

- Suppression of transcription factors and inflammatory cytokine gene expression.

Macrolides in the treatment of respiratory infection; 14-ring clarithromycin and 15-ring azithromycin are widely used. In the study on the effect of clarithromycin on viral respiratory infections; In prophylaxis and treatment of monkeys infected with influenza virus, interleukin (IL) -6 , IL-1 $\beta$ and IL-8 levels in lung tissues after treatment were shown to be lower than lungs of untreated monkeys (9).

Studies in people infected with Covid-19 have been shown to reduce the viral load with hydroxychloroquine and azithromycin therapy. Gautret et al in his study on patients with COVID-19; patients treated with hydroxychloroquine and azithromycin have been shown to have better results than those treated with hydroxychloroquine alone (10). In some studies, it has been observed that azithromycin alone was not effective against covid-19 in in-vitro environment. However, more effective results have been obtained, when azithromycin and hydroxychloroquine were used together. The authors think that this is due to the synergistic effect of the two drugs (11). The effect of azithromycin in the in vitro environment may differ from the in vivo environment, since in vitro environments cannot completely mimic the in vivo environment. The use of both azithromycin and hydroxychlorochine alone has not been as effective as combined use in clinical trials. However, it should be kept in mind that some patients, who use azithromycin with hydroxychloroquine may develop cardiac arrhythmias (12).

In this study, we aimed to investigate whether clarithromycin and azithromycin are effective molecules against COVID-19. In this study, the activities of analogues of FDA approved of azithromycin and clarithromycin against SARS-CoV2 virus were compared. Molecular structures of 381 analogues of clarithromycin and 122 analogues of azithromycin were downloaded from the PubChem website (https://pubchem.ncbi.nlm.nih.gov/). A total of 503 analogues of these two molecules were studied to target the RNA-dependent RNA polymerase protein of the SARS-CoV-2 virus. The proteins used for this purpose were 5W44 (13), 5FDD (14), 6E6V (15), 6FS8 (16), 6QX8 (17), 6NUR (18), and 6NUS (18). As the result of the calculations, the results of 503 analogues were compared with the results of azithromycin and clarithromycin using the numerical values of the parameters obtained. We tried to find more effective and high-activity molecules against SARS-CoV-2 virus's RNA-dependent RNA polymerase protein.

\section{Method}

In this study, the activities of azithromycin and clarithromycin in total 503 analogues, against SARS-CoV-2 virus RNA-dependent RNA polymerase protein were compared. In the calculations for this comparison, molecular docking calculations were made in the inter- action of the SARS-CoV-2 virus RNA-dependent RNA polymerase protein with a total of 503 analogues of azithromycin and clarithromycin. Maestro Molecular Modelling platform (version 12.2) by Schrödinger, LLC (19) was used for these calculations. The calculations made on the Maestro Molecular modelling platform consisted of several stages. Each stage is called a module, each of which works for a different task. The first module used in the Maestro Molecular modelling platform is the protein preparation module $(20$, 21 ), which is used to prepare the studied proteins for calculations.

In the protein preparation module, interactions of molecules with many others have been studied. Studied proteins were downloaded from the protein data bank site. IDs of these proteins are Crystal structure of the influenza virus PA endonuclease in complex (ID:5W44), Endonuclease inhibitor 1 bound to influenza strain H1N1 polymerase (ID:5FDD), The N-terminal domain of PA endonuclease from the influenza H1N1 virus (ID:6E6V), Influenza B/Memphis/13/03 endonuclease (ID:6FS8), Influenza A virus (ID:6QX8), SARS-Coronavirus NSP12 bound to NSP7 and NSP8 co-factors (ID:6NUR), and SARS-Coronavirus NSP12 bound to NSP8 co-factor (ID:6NUS). By using this module, at first, the water molecules in the structures of the proteins were deleted. Afterwards, optimizations of these proteins were made, binding methods and charges of proteins were calculated. After this optimization process, active regions of these proteins were determined. The proteins in the active regions of the studied proteins were given a mobility for interaction, because the mobility-free proteins can interact more easily with 503 analogues.

After that, a preparation of e for 503 analogues calculations with another module started, in the LigPrep module $(22,23)$. Physiological $\mathrm{pH}$ values $(\mathrm{pH}=5 \pm 4)$ of 503 analogues were calculated within this module. At this $\mathrm{pH}$ value, 3D structures of high-energy isomers of 503 analogues in accurate protonation were obtained and minimized at OPLS3e method.

The Glide ligand docking module was used to calculate the interactions of RNA-dependent RNA polymerase proteins of the SARS-CoV-2 virus with the 503 analogues. Many parameters were obtained from the calculations made using this module. Inhibition activities of molecules were predicted from the numerical values of these parameters. After interactions of 503 analogues with proteins, the parameters obtained were compared. ADME/T analysis (absorption, distribution, metabolism, excretion and toxicity) of molecules with a higher inhibition activity than the reference molecules azithromycin and clarithromycin were performed after this comparison. ADME/T analysis calculations were made with the Qik-prop module (24) of the Schrödinger software. The most important reason for these calculations with the Qik-prop module was that it was a guide for in vitro and in vivo experiments, because with these calculations, the effects and reactions of molecules in human metabolism were predicted.

\section{Result and discussion}

In this study, the activities of azithromycin and clarithromycin in total 503 analogues were compared against the RNA-dependent RNA polymerase protein of the SARS-CoV-2 virus. It should be 
known very well that as the interaction of these 503 analogues with the RNA-dependent RNA polymerase protein of the SARSCoV-2 virus, the inhibition activity of the molecule with a higher interaction will be higher (25-27). The RNA-dependent RNA polymerase protein of the SARS-CoV-2 virus of the molecule with a high inhibition activity will adhere more. This will prevent the
SARS-CoV-2 virus from replicating the RNA-dependent RNA polymerase protein itself, and this virus will be isolated. In this direction, many parameters have been obtained in the molecular docking calculations.

Azithromycin (PubChem ID: 447043) whose UIPAC name is $(2 \mathrm{R}, 3 \mathrm{~S}, 4 \mathrm{R}, 5 \mathrm{R}, 8 \mathrm{R}, 10 \mathrm{R}, 11 \mathrm{R}, 12 \mathrm{~S}, 13 \mathrm{~S}, 14 \mathrm{R})-11$ -

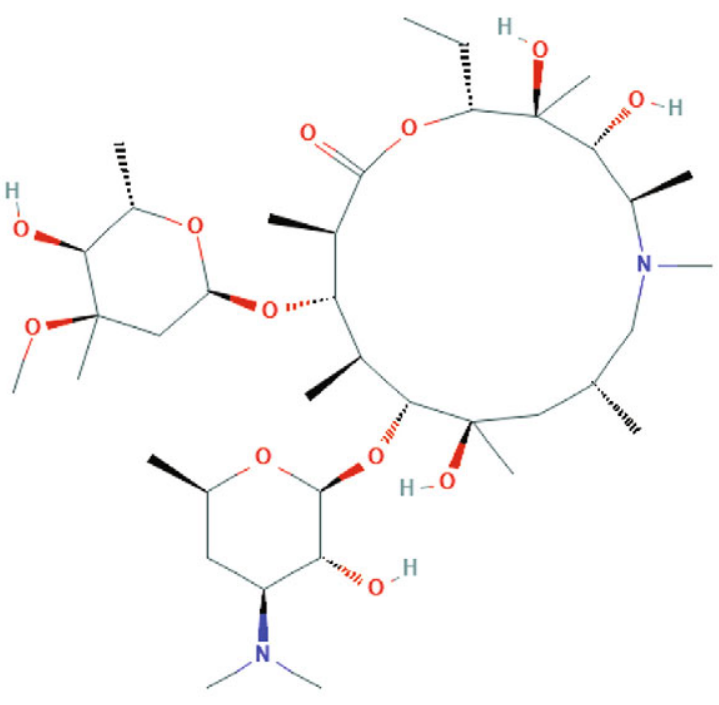

Azithromycin

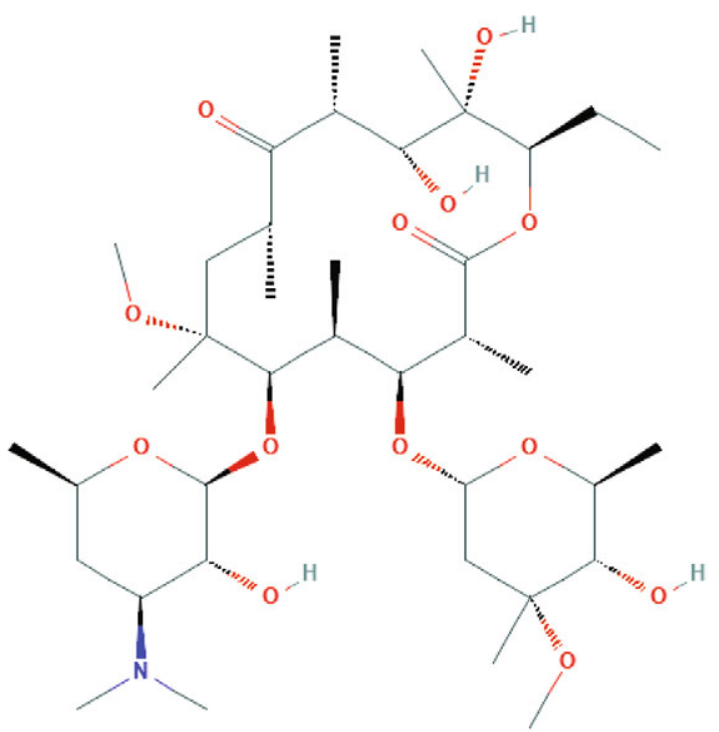

Clarithromycin

Fig. 1. Molecular structure of azithromycin and clarithromycin.
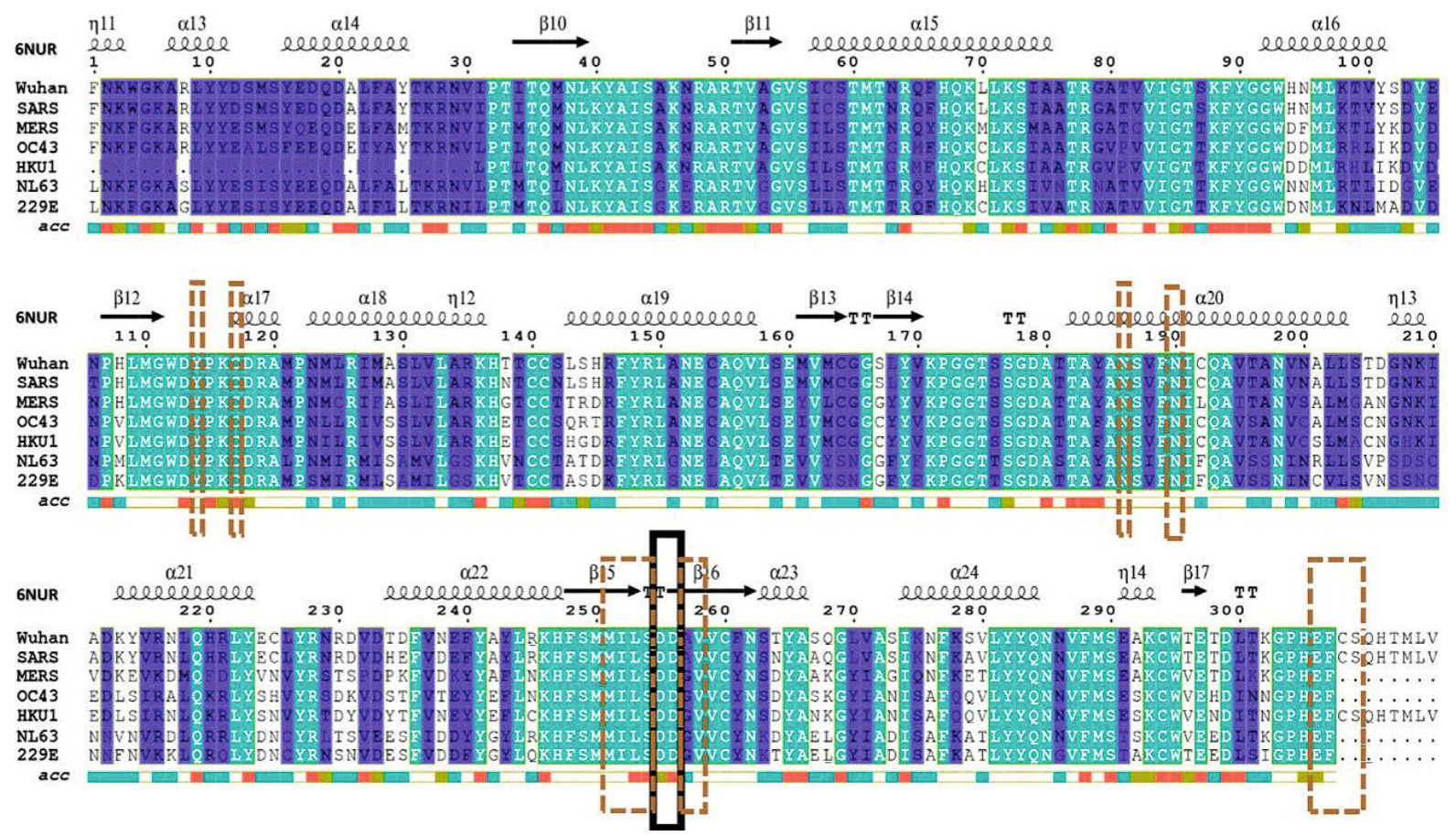

Fig. 2. Sequence alignment of the proteins from SARS-CoV2 with other CoVs. 
Tab. 1. The molecules interacted with target protein.

\begin{tabular}{lccccccc}
\hline Compound ID & 5FDD & 5W44 & 6E6V & 6FS8 & 6QX8 & 6NUR & 6NUS \\
\hline 9851445 & OS & OS & - & - & - & OS, PS & OS, PS \\
118859401 & OS, PS & OS & OS, PS & OS, PS & OS, PS & OS, PS & OS, PS \\
118859402 & OS, PS & OS, PS & OS, PS & OS, PS & OS, PS & OS & OS, PS \\
121370516 & OS, PS & OS, PS & OS, PS & OS, PS & OS & OS, PS & OS, PS \\
121370518 & OS, PS & OS, PS & OS, PS & OS, PS & OS, PS & OS, PS & OS, PS \\
121370520 & OS, PS & OS, PS & OS & OS, PS & OS, PS & OS, PS & OS, PS \\
121373522 & OS & OS, PS & OS, PS & OS, PS & OS, PS & OS, PS & OS, PS \\
123274687 & OS, PS & OS, PS & OS, PS & OS, PS & OS, PS & OS, PS & OS \\
126603996 & OS, PS & OS, PS & OS, PS & OS & OS, PS & OS, PS & OS, PS \\
\hline
\end{tabular}

OS - original Structure, PS - possible structure

[(2S,3R,4S,6R)-4-(dimethylamino)-3-hydroxy-6-methyloxan-2-yl]oxy-2-ethyl-3,4,10-trihydroxy-13-[(2R,4R,5S,6S)5 -hydroxy-4-methoxy-4,6-dimethyloxan-2-yl] oxy3,5,6,8,10,12,14-heptamethyl-1-oxa-6-azacyclopentadecan- 15-one and clarithromycin (PubChem ID: 84029) whose UIPAC name is (3R, 4S, 5S, 6R, 7R, 9R, 11R, 12R, 13S, 14R)-6-[(2S, 3R, 4S, 6R)-4-(dimethylamino)-3-hydroxy-6-methyloxan-2-yl]oxy-14-ethyl-12,13-dihydroxy-4-[(2R, 4R, 5S, 6S) -5-hydroxy-4-methoxy-4,6-dimethyloxan-2-yl]oxy-7-methoxy-3, 5, 7, 9, 11, 13-hexamethyl-oxacyclotetradecane-2,10-dione are presented in Figure 1.

In this study, the inhibitory activities of azithromycin and clarithromycin's 503 analogues against SARS-CoV2 proteins were compared. In all coronovirus varieties, RNA-dependent RNA polymerase (RdRp) is the most important enzyme in the cell that catalyses the replication of RNA from RNA templates. When the previous studies were examined, severe acute respira-

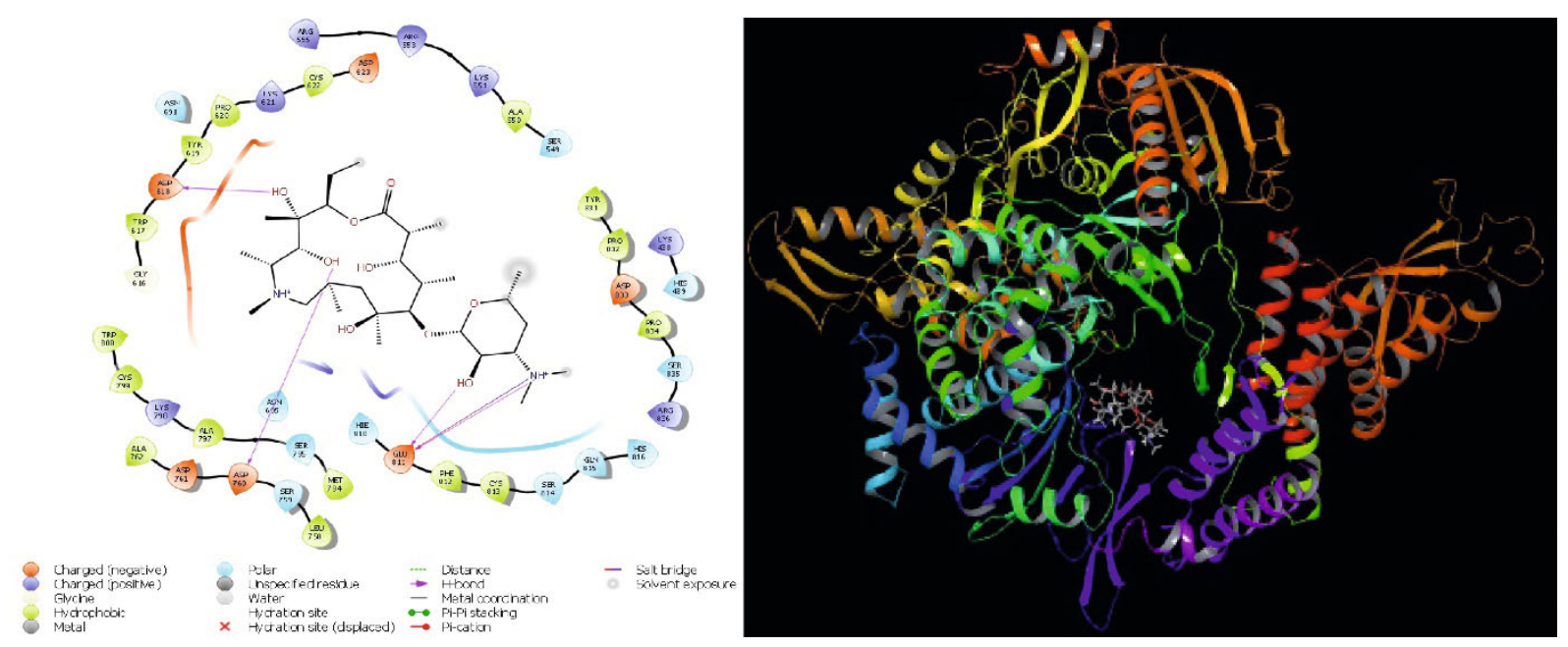

Fig. 3. The interaction schema at analogue 9851445 against 6NUR.

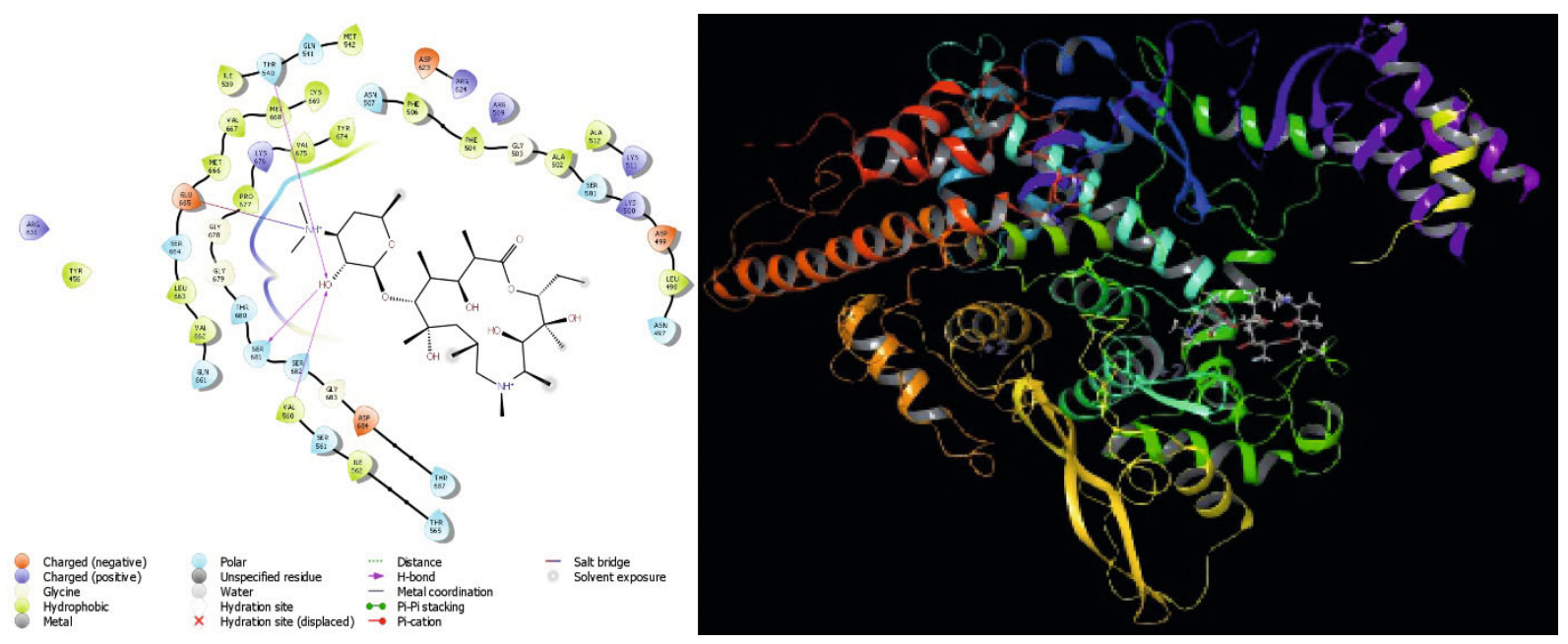

Fig. 4. The interaction schema at analogue 9851445 against 6NUS. 

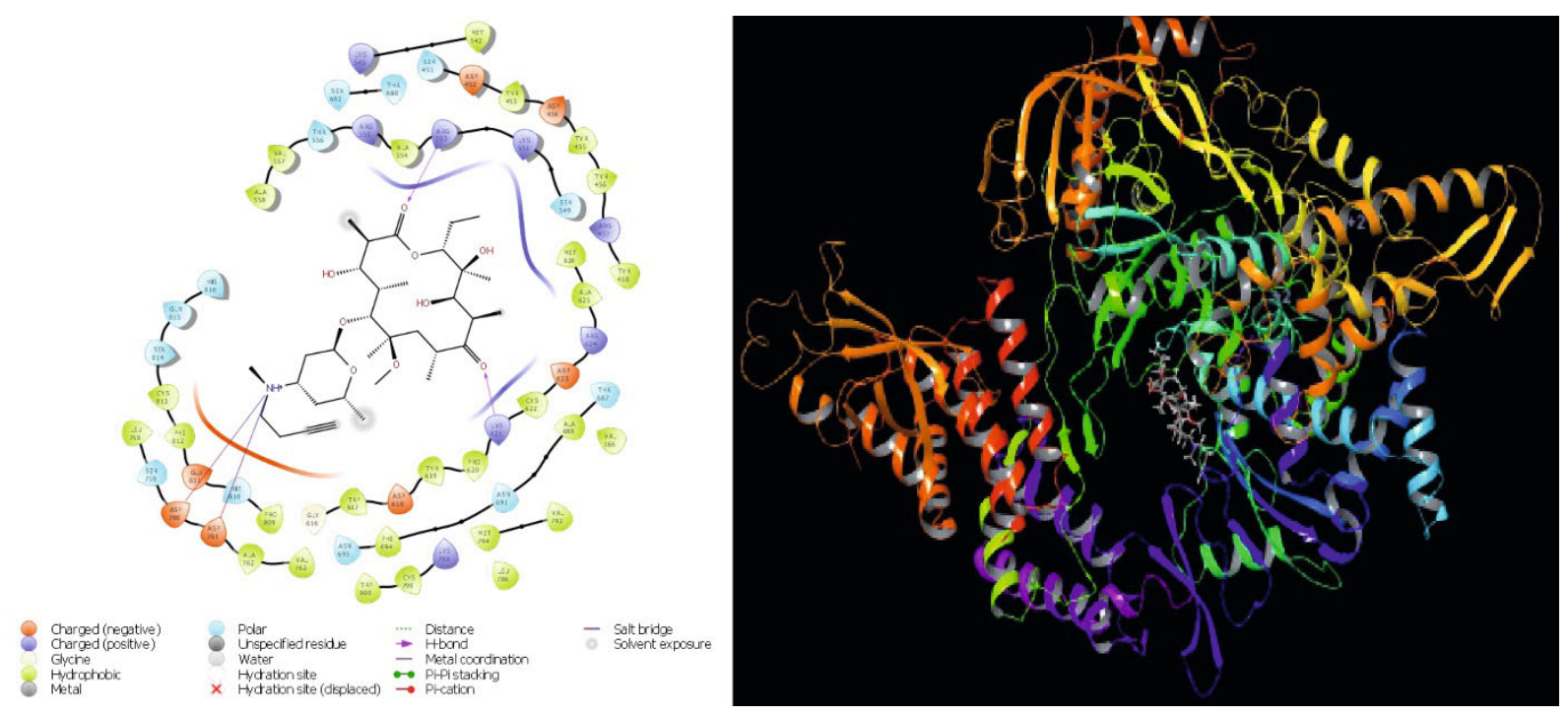

Fig. 5. The interaction schema at analogue 118859401 against 6NUR.
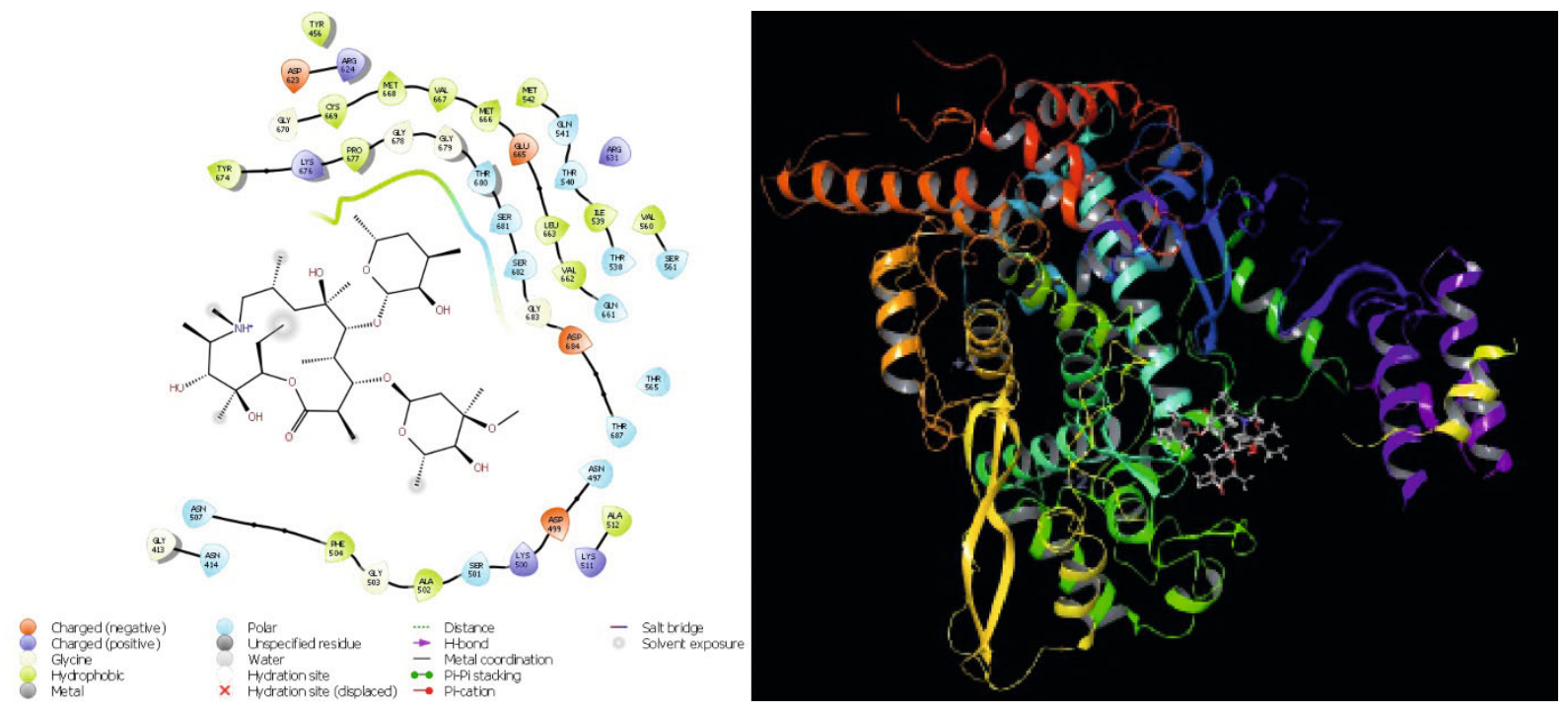

Fig. 6. The interaction schema at analogue 121373522 against 6NUS.

tory syndrome coronavirus (SARS-CoV), SARS-CoV-2, Middle East respiratory syndrome coronavirus (MERS-CoV), Human coronavirus OC43 (HCoV-OC43), Human coronavirus HKU1 (HCoV-HKU1) RNA-dependent RNA polymerase protein sequences of Human coronavirus NL63 (HCoV-NL63), and Human coronavirus 229E (HCoV-229E) have similar sequences, when compared to RNA-dependent RNA polymerase protein sequences and have structurally similar codes as shown in Figure 2 (28-30).

Molecular docking calculations were made as the result of interaction of these 503 analogues against SARS-CoV2 protein. In the calculations for the 503 analogues of azithromycin and clarithromycin, 37 analogues were found that showed an inhibition activity against the SARS-CoV2 protein. One of these analogues came from azithromycin and the remaining 36 from clarithromycin. As the result of the calculations, the inhibition activities of these 503 analogues against SARS-CoV2 RNA-dependent RNA polymerase protein were compared. Calculations for this comparison were made using the numerical values of the obtained parameters. The first parameter used for this comparison is the Docking Score (31-34), which is the most important parameter used to compare the inhibition activities of molecules. The molecule, which is the most negative molecule of this parameter, has the highest inhibition activity value. Analogues studied may have more than one stable structure. Accordingly, more than one structure of an analogue can interact with different points in the active 
Tab. 2. Numerical values of the parameters obtained from interaction of studied molecule with cancer cells.

\begin{tabular}{|c|c|c|c|c|c|c|c|c|c|}
\hline & Molecule & $\begin{array}{l}\text { Docking } \\
\text { Score }\end{array}$ & $\begin{array}{l}\text { Glide ligand } \\
\text { efficiency }\end{array}$ & $\begin{array}{l}\text { Glide } \\
\text { hbond }\end{array}$ & $\begin{array}{l}\text { Glide } \\
\text { evdw }\end{array}$ & $\begin{array}{l}\text { Glide } \\
\text { ecoul }\end{array}$ & $\begin{array}{c}\text { Glide } \\
\text { emodel }\end{array}$ & $\begin{array}{l}\text { Glide } \\
\text { energy }\end{array}$ & $\begin{array}{c}\text { Glide } \\
\text { einternal }\end{array}$ \\
\hline \multirow{6}{*}{ 5W44 } & 9851445 & -5.17 & -0.13 & -1.77 & -32.86 & -10.51 & -49.87 & -43.37 & 1.07 \\
\hline & 118859401 & -5.38 & -0.13 & -1.44 & -35.83 & -4.43 & -38.73 & -40.26 & 28.73 \\
\hline & 118859402 & -4.02 & -0.09 & -0.48 & -37.73 & -13.04 & -176.76 & -50.77 & 15.42 \\
\hline & 121370516 & -6.94 & -0.16 & -2.56 & -43.19 & -8.93 & -59.57 & -52.11 & 5.18 \\
\hline & 121370518 & -4.78 & -0.10 & -2.15 & -29.08 & -8.63 & -43.68 & -37.71 & 10.87 \\
\hline & 121370520 & -4.78 & -0.10 & -2.15 & -29.08 & -8.63 & -43.68 & -37.71 & 10.87 \\
\hline \multirow{7}{*}{$5 F D D$} & 9851445 & -5.81 & -0.14 & -1.83 & -15.84 & -8.54 & -42.07 & -24.38 & 2.46 \\
\hline & 118859401 & -7.52 & -0.17 & -1.44 & -29.19 & -11.51 & -51.93 & -40.71 & 6.51 \\
\hline & 118859402 & -5.83 & -0.12 & -2.01 & -30.60 & -12.37 & -65.75 & -42.97 & 1.71 \\
\hline & 121370516 & -7.32 & -0.17 & -1.45 & -27.67 & -12.68 & -53.73 & -40.35 & 9.78 \\
\hline & 121370518 & -6.90 & -0.15 & -1.17 & -33.26 & -7.41 & -47.90 & -40.67 & 3.38 \\
\hline & 121370520 & -6.90 & -0.15 & -1.17 & -33.26 & -7.41 & -47.90 & -40.67 & 3.38 \\
\hline & 121373522 & -6.32 & -0.13 & -2.40 & -27.52 & -6.31 & -43.07 & -33.83 & 14.15 \\
\hline \multirow{6}{*}{$6 \mathrm{E} 6 \mathrm{~V}$} & 118859401 & -3.36 & -0.08 & -0.96 & -19.54 & -9.60 & -2.89 & -29.14 & 7.86 \\
\hline & 118859402 & -2.92 & -0.06 & -1.88 & -26.36 & 0.13 & -20.38 & -26.22 & 25.15 \\
\hline & 121370516 & -3.91 & -0.09 & -1.45 & -18.07 & -10.45 & -0.52 & -28.52 & 18.68 \\
\hline & 121370518 & -5.32 & -0.11 & -2.00 & -30.71 & -8.78 & -43.98 & -39.49 & 0.00 \\
\hline & 121370520 & -5.32 & -0.11 & -2.00 & -30.71 & -8.78 & -43.98 & -39.49 & 0.00 \\
\hline & 121373522 & -4.62 & -0.09 & -2.12 & -27.75 & -7.92 & -30.38 & -35.67 & 4.08 \\
\hline \multirow{7}{*}{$6 \mathrm{FS} 8$} & 9851445 & - & - & - & - & - & - & - & - \\
\hline & 118859401 & -4.90 & -0.11 & -1.21 & -25.39 & -15.21 & -58.09 & -40.60 & 0.00 \\
\hline & 118859402 & -3.99 & -0.08 & -1.76 & -12.28 & -16.65 & -31.32 & -28.94 & 5.01 \\
\hline & 121370516 & -5.80 & -0.13 & -2.59 & -22.25 & -20.44 & -63.09 & -42.69 & 6.78 \\
\hline & 121370518 & -5.76 & -0.12 & -1.56 & -26.27 & -12.43 & -48.96 & -38.70 & 6.66 \\
\hline & 121370520 & -5.76 & -0.12 & -1.56 & -26.27 & -12.43 & -48.96 & -38.70 & 6.66 \\
\hline & 121373522 & -6.23 & -0.12 & -3.54 & -26.27 & -6.68 & -41.36 & -32.95 & 9.00 \\
\hline \multirow{5}{*}{ 6QX8 } & 9851445 & - & - & - & - & - & - & - & - \\
\hline & 118859401 & -4.36 & -0.10 & -1.49 & -30.83 & -10.34 & -42.98 & -41.17 & 10.79 \\
\hline & 121370518 & -4.61 & -0.10 & -1.92 & -30.75 & -8.26 & -46.35 & -39.01 & 3.61 \\
\hline & 121370520 & -4.61 & -0.10 & -1.92 & -30.75 & -8.26 & -46.35 & -39.01 & 3.61 \\
\hline & 121373522 & -5.59 & -0.11 & -3.18 & -20.19 & -18.50 & -37.81 & -38.69 & 12.12 \\
\hline \multirow{7}{*}{ 6NUR } & 9851445 & -9.83 & -0.24 & -3.45 & -24.46 & -20.10 & -51.67 & -44.56 & 7.37 \\
\hline & 118859401 & -6.57 & -0.15 & -2.46 & -26.11 & -11.70 & -48.01 & -37.81 & 13.46 \\
\hline & 118859402 & -3.02 & -0.06 & -2.78 & -29.29 & -14.48 & -48.85 & -43.78 & 13.44 \\
\hline & 121370516 & -3.14 & -0.07 & -1.44 & -26.43 & -10.32 & -29.03 & -36.74 & 9.95 \\
\hline & 121370518 & -3.58 & -0.08 & -0.90 & -35.71 & -9.86 & -57.81 & -45.58 & 3.73 \\
\hline & 121370520 & -3.58 & -0.08 & -0.90 & -35.71 & -9.86 & -57.81 & -45.58 & 3.73 \\
\hline & 121373522 & -5.91 & -0.12 & -2.40 & -36.12 & -12.33 & -62.15 & -48.45 & 0.00 \\
\hline \multirow{7}{*}{ 6NUS } & 9851445 & -6.11 & -0.15 & -2.77 & -25.53 & -10.77 & -41.28 & -36.30 & 5.87 \\
\hline & 118859401 & -3.14 & -0.07 & -1.91 & -21.96 & -6.32 & -34.87 & -28.29 & 3.35 \\
\hline & 118859402 & -3.83 & -0.08 & -1.95 & -27.00 & -6.74 & -34.53 & -33.74 & 7.16 \\
\hline & 121370516 & -5.54 & -0.13 & -1.18 & -29.27 & -6.39 & -21.69 & -35.65 & 21.18 \\
\hline & 121370518 & -5.46 & -0.12 & -1.30 & -32.69 & -6.86 & -38.73 & -39.55 & 11.82 \\
\hline & 121370520 & -5.46 & -0.12 & -1.30 & -32.69 & -6.86 & -38.73 & -39.55 & 11.82 \\
\hline & 121373522 & -5.73 & -0.11 & -2.40 & -19.34 & -1.68 & 11.62 & -21.02 & 11.90 \\
\hline
\end{tabular}

region of proteins. Interactions can occur both with the original structure and with the possible structure of the analogues. The structures of the interactions obtained as the result of the calculations are given in Table 1. If one or more isomers of an analogue interact more than once, the interaction with the most negative value is taken into account in the comparison operations.

Another parameter is the Glide ligand efficiency, which shows the numerical value of the activity of molecules. The next pa- rameter is the Glide hbond (35), which is the numerical value of hydrogen bonds formed by interactions between molecules and proteins. The next parameters are the Glide evdw and Glide ecoul (36), which is a numerical value of Van Der Walls bonds and Coulumb interactions between the molecules and proteins. The next parameter is the Glide emodel (37), which shows the energy of the docking model resulting from the interaction. The next parameter is the Glide energy (38), which is a modified Coulomb-van der 
Tab. 3. ADME properties of molecules.

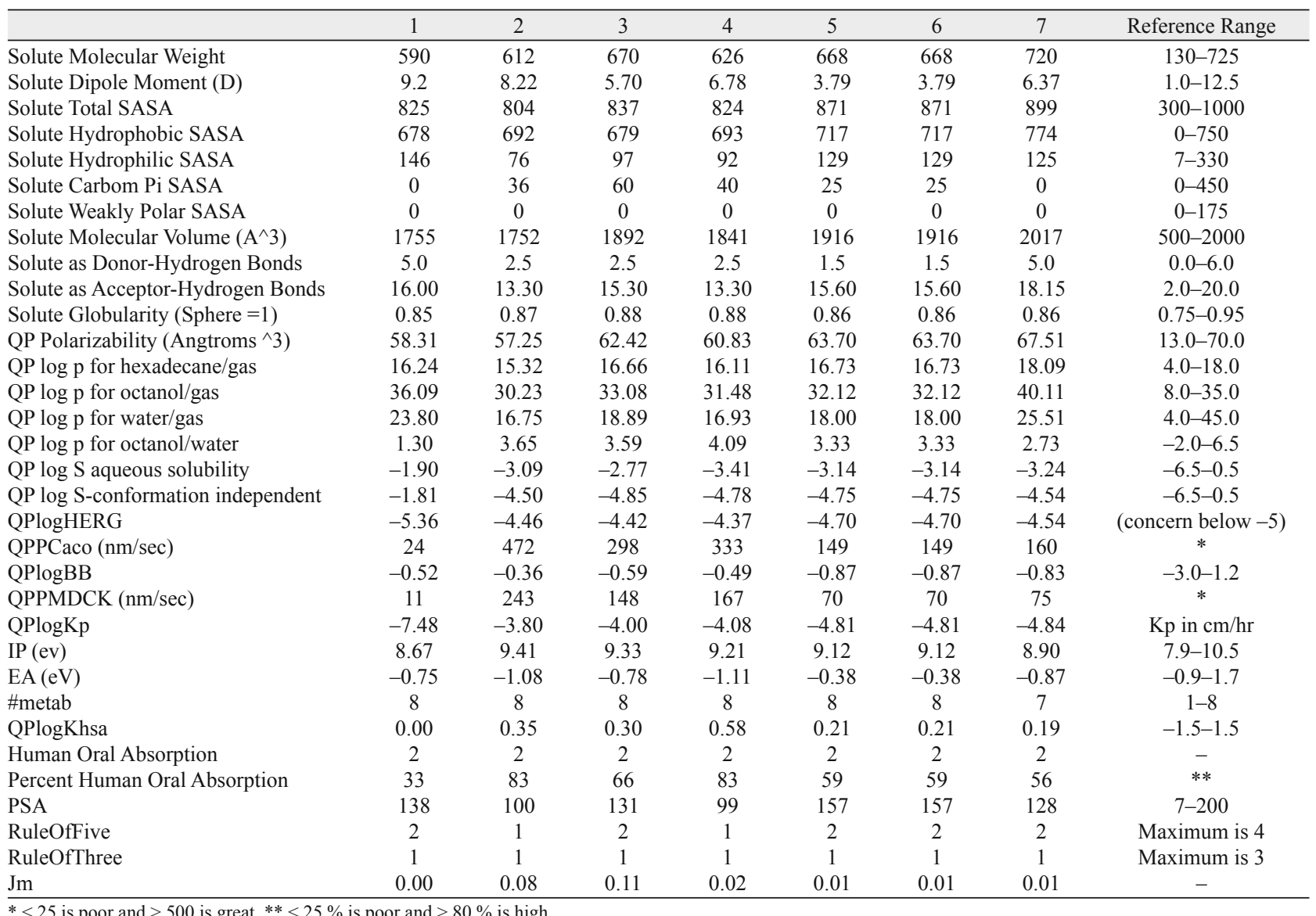

$*<25$ is poor and $>500$ is great, $* *<25 \%$ is poor and $>80 \%$ is high

Waals interaction energy. The last parameter is the Glide einternal (39), which is Internal torsional energy.

Interactions between the analogues and protein are the most important factors affecting the inhibition activity of molecules in Figure 3, 4, 5 and 6. Other interactions are provided with supplementary data in Figure S1-S5. These interactions have many interactions such as: hydrogen bonds, polar and hydrophobic interactions, $\pi-\pi$ and halogen bonds (40-43).

The results of the molecular docking calculations are evaluated in the Tables 1 and 2. When the inhibition activities of the 503 analogues of azithromycin and clarithromycin against the SARSCoV2 virus were compared, it was observed that the analogues had a similar order of docking score and the Glide energy parameters. Since the ID numbers of the molecules given in Table 2 are long, their names are as follows; 1 (9851445), 2 (118859401), 3 (118859402), 4 (121370516), 5 (121370518), 6 (121370520), 7 (121373522). These molecules in Table 1 and 2 have been chosen because they have both numerical values of these two parameters and the number of structures of analogues interacting with proteins, which are better than those of other analogues.

In this study, the SARS-CoV2 virus is 6NUR and 6NUS, which is the RNA-dependent RNA polymerase protein. Among these proteins, the best inhibitor among the 503 analogues according to the docking score parameter is 9851445 with a great difference. This analogue is the analogue of azithromycin. On the other hand, 118859401 and 121373522 have the highest inhibitory activity among 381 analogues of clarithromycin, but these analogues did not show a good inhibitory activity like 9851445 . Another parameter is the Glide ligand efficiency, the numerical values of this parameter are very similar to the docking score parameter. The numerical value of this parameter is the analogue with the most negative value and the highest biological activity. Accordingly, 9851445 and 118859401 analogues were the most negative analogues for the 6NUR, 9851445 and 121373522 for 6NUS ligand activity. The calculations showed that 9851445,118859401 , and 121373522 analogues indicated that the results against the SARSCoV2 virus RNA-dependent RNA polymerase protein were better than all the analogues of clarithromycin and azithromycin.

These analogues were found to have better docking score parameters than other molecules. In this study, it was found that analogues with the best inhibition activity against proteins were found to stop the virus by blocking the RNA-dependent RNA polymerase protein of the SARS-CoV-2 virus. In this study, 37 out of 503 analogues interacted with proteins, among which 7 the SARS- 
101-110

CoV-2 virus RNA-dependent RNA polymerase protein inhibition activity was higher than the others. After examining the docking parameters of these analogues, ADME/T analysis (Absorption, distribution, metabolism, excretion, and toxicity) (44-47) should be done to examine the effects and responses of these analogues in human metabolism. As the result of this analysis, many parameters were obtained. The numerical values of these parameters showed how these analogues act in human metabolism and how they react in organs.

There are many important parameters among the parameters obtained as the result of ADME/T analysis. The most important of these are; The Solute Molecular Weight (48) parameter tells the numerical value of the molecular weight of the molecules; Solute Hydrophobic SASA (49) is the hydrophobic component of the SASA (saturated carbon and attached hydrogen); The Solute Molecular Volume (50) parameter tells the molecular volume of analogues; Solute as Donor-Hydrogen Bonds (51) shows the numerical value of the number of hydrogen bonds formed between analogues and proteins; QP log p for octanol/gas (52) is predicted octanol/gas partition coefficient; QPlogHERG (53) is predicted IC50 value for blockage of HERG $\mathrm{K}^{+}$channels; QPPCaco (54) is predicted apparent Caco-2 cell permeability in $\mathrm{nm} / \mathrm{sec}$. Caco2 cells are a model for the gut-blood barrier; QPPMDCK (55) is predicted apparent MDCK cell permeability in $\mathrm{nm} / \mathrm{sec}$. MDCK cells are considered to be a good mimic for the blood-brain Barrier. QPlogKhsa (56) is prediction of binding to human serum albumin; RuleOfFive (57) is number of violations of Lipinski's rule of five, which is also known as the 5 rules of Pfizer. The rules are: mol_MW $<500, \mathrm{QP} \operatorname{logPo} / \mathrm{w}<5$, donorHB $\leq 5$, accptHB $\leq$ 10. Compounds that satisfy these rules are considered druglike; RuleOfThree (58) is number of violations of Jorgensen's rule of three. The three rules are: QPlogS $>-5.7, \mathrm{QP}$ PCaco $>22 \mathrm{~nm} / \mathrm{s}$, \# Primary Metabolites $<7$. Considering the numerical values of these parameters, it was observed that they did not provide the conditions for some parameters.

\section{Conclusions}

Inhibition activities of azithromycin and clarithromycin analogues against SARS-CoV-2 virus against RNA-dependent RNA polymerase proteins were compared. Against the 6SUR, the SARS-Coronavirus virus protein, the two most negative analogues of the docking score parameter were 9851445 whose IUPAC Name is $(2 R, 3 S, 4 R, 5 R, 8 R, 10 R, 11 R$ ,12S,13S,14R)-11-[(2S,3R,4S,6R)-4-(dimethylamino)-3-hydroxy -6-methyloxan-2-yl]oxy-2-ethyl-3,4,10,13-tetrahydroxy3,5,6,8,10,12,14-heptamethyl-1-oxa-6-azacyclopentadecan15 -one and the other was 118859401 whose IUPAC Name is $(3 R, 4 S, 5 S, 6 R, 7 R, 9 R, 11 R, 12 R, 13 S, 14 R)-6-[(4 S, 6 R)-4-[$ but-3ynyl(methyl)amino]-6-methyloxan-2-yl]oxy-14-ethyl-4,12,13trihydroxy-7-methoxy-3,5,7,9,11,13-hexamethyl-oxacyclotetradecane-2,10-dione. Against the 6NUS, another SARS-Coronavirus virus protein, the two most negative analogues of the docking score parameter were 9851445 and 121373522 whose IUPAC Name is $(2 R, 3 S, 4 R, 5 R, 8 R, 10 R, 11 R, 12 S, 13 S, 14 R)$-2-ethyl-3,4,10-
trihydroxy-11-[(2S,3R,6R)-3-hydroxy-4,6-dimethyloxan-2-yl]oxy$13-[(2 R, 4 R, 5 S, 6 S)-5$-hydroxy-4-methoxy-4,6-dimethyloxan-2-yl] oxy-3,5,6,8,10,12,14-heptamethyl-1-oxa-6-azacyclopentadecan15-one. Accordingly, these three molecules were found to have the best inhibition activity. As the result of the comparison, ADME/T analysis of the molecules with the highest inhibition activities was performed. As the result of this analysis, the effects of analogues on human metabolism have been foreseen. These results will be an important guide for further in vitro and in vivo studies.

\section{References}

1. Wang D, Hu B, Hu C, Zhu F, Liu X, Zhang J, et al. Clinical characteristics of 138 hospitalized patients with 2019 novel coronavirus-infected pneumonia in Wuhan, China. Jama 2020; 323 (11): 1061-1069.

2. Corman VM, Muth D, Niemeyer D, Drosten C. Hosts and sources of endemic human coronaviruses. Advances in virus research. 100: Elsevier; 2018. p. 163-188.

3. Organization WH. Naming the coronavirus disease (COVID-19) and the virus that causes it 2020. URL https: //www who int/emergencies/diseases/ novel-coronavirus-2019/technical-guidance/naming-the-coronavirus-disease- (covid-2019)-and-the-virus-that-causes-it 2020.

4. Millán-Oñate J, Millan W, Mendoza LA, Sánchez CG, FernandezSuarez H, Bonilla-Aldana DK, et al. Successful recovery of COVID-19 pneumonia in a patient from Colombia after receiving chloroquine and clarithromycin. Ann Clin Microbiol Antimicrob 2020; 19: 1-9.

5. Heneghan C, Aronson J, Hobbs R, Mahtani K. Rapidly managing pneumonia in older people during a pandemic 2020 .

6. Huang W-H, Teng L-C, Yeh T-K, Chen Y-J, Lo W-J, Wu M-J et al. 2019 novel coronavirus disease (COVID-19) in Taiwan: Reports of two cases from Wuhan, China. J Microbiol Immunol Infection 2020.

7. Scheld WM, Whitman MS, Tunkel AR. Azithromycin and clarithromycin overview and comparison with erythromycin. Infection Control \& Hospital Epidemiology. 1992; 13 (6): 357-368.

8. Min J-Y, Jang YJ. Macrolide therapy in respiratory viral infections. Mediators Inflamm 2012; 2012.

9. Arikata M, Itoh Y, Shichinohe S, Nakayama M, Ishigaki H, Kinoshita $\mathbf{T}$ et al. Efficacy of clarithromycin against H5N1 and H7N9 avian influenza a virus infection in cynomolgus monkeys. Antiviral Res 2019; 171: 104591

10. Hulme OJ, Wagenmakers EJ, Damkier P, Madelung CF, Siebner HR, Helweg-Larsen $\mathbf{J}$ et al. A Bayesian reanalysis of the effects of hydroxychloroquine and azithromycin on viral carriage in patients with COVID-19. medRxiv 2020.

11. Andreania J, Le Bideaua M, Duflota I, Jardota P, Rollanda C, Boxbergera $\mathbf{M}$ et al. In vitro testing of hydroxychloroquine and azithromycin on SARS-CoV-2 shows 1 synergistic effect 2. Lung 2020; 21: 22.

12. Mitra RL, Greenstein SA, Epstein LM. An algorithm for managing QT prolongation in Coronavirus Disease 2019 (COVID-19) patients treated with either chloroquine or hydroxychloroquine in conjunction with azithromycin: Possible benefits of intravenous lidocaine. Heart Rhythm Case Reports 2020; 6 (5): 244.

13. Beylkin D, Kumar G, Zhou W, Park J, Jeevan T, Lagisetti C et al. Protein-Structure Assisted Optimization of 4, 5-Dihydroxypyrimidine6-Carboxamide Inhibitors of Influenza Virus Endonuclease. Sci Reports 2017; 7 (1): 1-12. 
14. Fudo S, Yamamoto N, Nukaga M, Odagiri T, Tashiro M, Hoshino T. Two distinctive binding modes of endonuclease inhibitors to the N-terminal region of influenza virus polymerase acidic subunit. Biochemistry 2016; 55 (18): 2646-2660.

15. Credille CV, Morrison CN, Stokes RW, Dick BL, Feng Y, Sun J et al. SAR Exploration of Tight-Binding Inhibitors of Influenza Virus PA Endonuclease. J Med Chem 2019; 62 (21): 9438-9449.

16. Omoto S, Speranzini V, Hashimoto T, Noshi T, Yamaguchi H, Kawai $\mathrm{M}$ et al. Characterization of influenza virus variants induced by treatment with the endonuclease inhibitor baloxavir marboxil. Sci Reports 2018; 8 (1): $1-15$.

17. Fan H, Walker AP, Carrique L, Keown JR, Martin IS, Karia D et al. Structures of influenza A virus RNA polymerase offer insight into viral genome replication. Nature 2019; 573 (7773): 287-90.

18. Kirchdoerfer RN, Ward AB. Structure of the SARS-CoV nsp 12 polymerase bound to nsp7 and nsp8 co-factors. Nature Comm 2019; 10 (1): 1-9.

19. Schrodinger L. Small-Molecule Drug Discovery Suite 2019-4 2019. New York, NY: Schrodinger, LLC 2019.

20. Epik SL. New York NY, 2019-4. Impact, Schrödinger, LLC, New York, NY 2016; Protein Preparation Wizard.

21. Friesner RA, Murphy RB, Repasky MP, Frye LL, Greenwood JR, Halgren TA et al. Extra precision glide: Docking and scoring incorporating a model of hydrophobic enclosure for protein- ligand complexes. J Med Chem 2006; 49 (21): 6177-6196.

22. Sastry GM, Adzhigirey M, Day T, Annabhimoju R, Sherman W. Protein and ligand preparation: parameters, protocols, and influence on virtual screening enrichments. J Comp Mol Design 2013; 27 (3): 221-234.

23. Release S. LigPrep, Schrödinger, LLC, New York, NY, 2019-4. New York, NY 2019.

24. Release S. QikProp, Schrödinger, LLC, New York, NY, 2019-4. New York, NY 2019.

25. Bilgiçli HG, Ergön D, Taslimi P, Tüzün B, Kuru İA, Zengin M et al. Novel Propanolamine Derivatives Attached to 2-Metoxifenol Moiety: Synthesis, Characterization, Biological Properties, and Molecular Docking Studies. Bioorganic Chem 2020: 103969.

26. Türkan F, Taslimi P, Abdalrazaq SM, Aras A, Erden Y, Celebioglu HU et al. Determination of anticancer properties and inhibitory effects of some metabolic enzymes including acetylcholinesterase, butyrylcholinesterase, alpha glycosidase of some compounds with molecular docking study. J Biomol Struct Dynamics 2020 (just-accepted): 1-17.

27. Taslimi P, Erden Y, Mamedov S, Zeynalova L, Ladokhina N, Tas R et al. The Biological Activities, Molecular Docking Studies, and Anticancer Effects of 1-Arylsuphonylpyrazole Derivatives. J Biomol Struct Dynamics 2020 (just-accepted): 1-20.

28. Lung J, Lin YS, Yang YH, Chou YL, Shu LH, Cheng YC et al. The potential chemical structure of anti-SARS-CoV-2 RNA-dependent RNA polymerase. J Med Virol 2020; 92 (6): 693-697.

29. Elfiky AA. Anti-HCV, nucleotide inhibitors, repurposing against COVID-19. Life Sci 2020: 117477.

30. Wu C, Liu Y, Yang Y, Zhang P, Zhong W, Wang Y et al. Analysis of therapeutic targets for SARS-CoV-2 and discovery of potential drugs by computational methods. Acta Pharm Sinica B 2020.

31. Zengin G, Stefanucci A, Rodrigues MJ, Mollica A, Custodio L, Aumeeruddy MZ et al. Scrophularia lucida L. as a valuable source of bioactive compounds for pharmaceutical applications: in vitro antioxidant, anti-inflammatory, enzyme inhibitory properties, in silico studies, and HPLC profiles. J Pharm Biomed Analysis 2019; 162: 225-233.

32. Atmaca U, Kaya R, Karaman HS, Celik M, Gülçin İ. Synthesis of oxazolidinone from enantiomerically enriched allylic alcohols and determination of their molecular docking and biologic activities. Bioorganic Chem 2019; 88: 102980.

33. Menteşe E, Akyüz G, Emirik M, Baltaş N. Synthesis, in vitro urease inhibition and molecular docking studies of some novel quinazolin-4 $(3 \mathrm{H})$-one derivatives containing triazole, thiadiazole and thiosemicarbazide functionalities. Bioorganic Chem 2019; 83: 289-296.

34. Subhani S, Jayaraman A, Jamil K. Homology modelling and molecular docking of MDR1 with chemotherapeutic agents in non-small cell lung cancer. Biomed Pharmacother 2015; 71: 37-45.

35. Uysal A, Ozer OY, Zengin G, Stefanucci A, Mollica A, Picot-Allain CMN et al. Multifunctional approaches to provide potential pharmacophores for the pharmacy shelf: Heracleum sphondylium L. subsp. ternatum (Velen.) Brummitt. Computat Biol Chem 2019; 78: 64-73.

36. Taslimi P, Türkan F, Cetin A, Burhan H, Karaman M, Bildirici I et al. Pyrazole [3, 4-d] pyridazine derivatives: Molecular docking and explore of acetylcholinesterase and carbonic anhydrase enzymes inhibitors as anticholinergics potentials. Bioorganic Chem 2019; 92: 103213.

37. Özdemir Z, Sari S, Karakurt A, Dalkara S. Synthesis, anticonvulsant screening, and molecular modeling studies of new arylalkylimidazole oxime ether derivatives. Drug Develop Res 2019; 80 (2): 269-280.

38. Alim Z, Kiliç D, Demir Y. Some indazoles reduced the activity of human serum paraoxonase 1, an antioxidant enzyme: in vitro inhibition and molecular modeling studies. Arch Physiol Biochem 2019; 125 (5): 387-395.

39. Wang J-L, Li L, Hu M-B, Wu B, Fan W-X, Peng W et al. In silico drug design of inhibitor of nuclear factor kappa B kinase subunit beta inhibitors from 2-acylamino-3-aminothienopyridines based on quantitative structure-activity relationships and molecular docking. Computat Biol Chem 2019; 78: 297-305.

40. Sayin K, Üngördü A. Investigations of structural, spectral and electronic properties of enrofloxacin and boron complexes via quantum chemical calculation and molecular docking. Spectrochimica Acta Part A: Mol Biomol Spectroscopy 2019; 220: 117102.

41. Sayin K, Karakaş D. Investigation of structural, electronic properties and docking calculations of some boron complexes with norfloxacin: A computational research. Spectrochimica Acta Part A: Mol Biomol Spectroscopy 2018; 202: 276-283.

42. Sayin K, Karakaş D. Quantum chemical investigation of levofloxacin-boron complexes: a computational approach. J Mol Structe 2018; 1158: 57-65.

43. Sayin K, Karakaş D. Determination of structural, spectral, electronic and biological properties of tosufloxacin boron complexes and investigation of substituent effect. J Mol Struct 2017; 1146: 191-197.

44. Mermer A, Demirbas N, Uslu H, Demirbas A, Ceylan S, Sirin Y. Synthesis of novel Schiff bases using green chemistry techniques; antimicrobial, antioxidant, antiurease activity screening and molecular docking studies. J Mol Struct 2019; 1181: 412-422.

45. Nadaroglu H, Gungor Aa, Gundogdu Ö, Kishali Nh, Sever B, Altintop Md. Investigation of the inhibitory effects of isoindoline-1, 3-dion derivatives on hCA-I and hCA-II enzyme activities. J Mol Struct 2019; 1197: 386-392. 


\section{1-110}

46. Sari S, Barut B, Özel A, Kuruüzüm-Uz A, Şöhretoğlu D. Tyrosinase and $\alpha$-glucosidase inhibitory potential of compounds isolated from Quercus coccifera bark: in vitro and in silico perspectives. Bioorganic Chem 2019; 86: 296-304.

47. Şener Lt, Gündüz Sk, Şener A, Bicak B, Kökcü Y, Albeniz İ. Computerised designing of doxorubicin with breast cancer cells. İstanbul Tip Fakültesi Dergisi 2019; 82 (1): 40-46.

48. Celik I, Erol M, Temiz Arpaci O, Sezer Senol F, Erdogan Orhan I. Evaluation of activity of some 2, 5-disubstituted benzoxazole derivatives against acetylcholinesterase, butyrylcholinesterase and tyrosinase: ADME prediction, DFT and comparative molecular docking studies. Polycyclic Aromatic Compounds 2020: 1-12.

49. Mermer A, Bayrak H, Şirin Y, Emirik M, Demirbaş N. Synthesis of novel Azol- $\beta$-lactam derivatives starting from phenyl piperazine and investigation of their antiurease activity and antioxidant capacity comparing with their molecular docking studies. J Mol Struct 2019; 1189: 279-287.

50. Budama-Kilinc Y, Cakir-Koc R, Kecel-Gunduz S, Zorlu T, Kokcu Y, Bicak B et al. Papain Loaded Poly ( $\varepsilon$-Caprolactone) Nanoparticles: In-silico andIn-Vitro Studies. J Fluorescence 2018; 28 (5): 1127-1142.

51. Bicak B, Gündüz SK, Kökcü Y, Özel AE, Akyüz S. Molecular docking and molecular dynamics studies of 1-glycyl-1-glutamic acid dipeptide. Bilge Internat J Sci Technol Res 2019; 3 (1): 1-9.

52. Sağlik BN, Çevik UA, Osmaniye D, Levent S, Çavuşoğlu BK, Demir Y et al. Synthesis, molecular docking analysis and carbonic anhydrase I-II inhibitory evaluation of new sulfonamide derivatives. Bioorganic Chem 2019; 91: 103153.
53. Sağlik BN, Çavuşoğlu BK, Osmaniye D, Levent S, Çevik UA, Ilgin $\mathbf{S}$, et al. In vitro and in silico evaluation of new thiazole compounds as monoamine oxidase inhibitors. Bioorganic Chem 2019; 85: 97-108.

54. Ertas M, Sahin Z, Bulbul EF, Bender C, Biltekin SN, Berk B, et al. Potent ribonucleotide reductase inhibitors: Thiazole-containing thiosemicarbazone derivatives. Arch Pharm 2019; 352 (11): 1900033.

55. Bayindir S, Caglayan C, Karaman M, Gülcin İ. The green synthesis and molecular docking of novel $\mathrm{N}$-substituted rhodanines as effective inhibitors for carbonic anhydrase and acetylcholinesterase enzymes. Bioorganic Chem 2019; 90: 103096.

56. Altindağ FD, Sağlik BN, Acar Çevik U, Işikdağ İ, Özkay Y, Karaca Gençer H. Novel imidazole derivatives as antifungal agents: Synthesis, biological evaluation, ADME prediction and molecular docking studies. Phosphorus, Sulfur, and Silicon and the Related Elements 2019; 194 (9): 887-894.

57. Lipinski CA, Lombardo F, Dominy BW, Feeney PJ. Experimental and computational approaches to estimate solubility and permeability in drug discovery and development settings. Adv Drug Deliv Rev 1997; 23 (1-3): 3-25.

58. Jorgensen WL, Duffy EM. Prediction of drug solubility from structure. Adv Drug Deliv Rev 2002; 54 (3): 355-366.

Received August 8, 2020. Accepted September 24, 2020. 